\title{
Treatment Patterns and Pharmacoutilization in Patients Affected by Psoriasis: An Observational Study in an Italian Real-World Setting
}

\author{
Valentina Perrone ${ }^{1}$ (1) $\cdot$ Serena Losi ${ }^{2} \cdot$ Alessia Maiorino $^{2} \cdot$ Silvia Antonelli $^{2} \cdot$ Massimo Giovannitti $^{3} \cdot$ Elisa Giacomini $^{1}$. \\ Diego Sangiorgi ${ }^{1} \cdot$ Luca Degli Esposti $^{1}$
}

Accepted: 28 December 2021 / Published online: 18 January 2022

(c) The Author(s) 2022

\begin{abstract}
Background Real-world data can inform the use of biologics for psoriasis (PSO).

Objective The aim was to evaluate treatment patterns and analyze pharmacoutilization in PSO patients in a real-world Italian setting, with a focus on the biologics most recently introduced.

Methods An observational study based on administrative databases was conducted. Patients were included based on PSO diagnosis identified by either discharge diagnosis or exemption code or prescription of anti-psoriatic topical drugs (proxy of diagnosis). To describe patient characteristics and treatment patterns using the most up-to-date data, two different approaches were used: a cross-sectional study performed during 2016-2018, and a longitudinal study conducted with patients who received their first biological/targeted synthetic drugs (naïve patients) in 2014 and 2017 (the inclusion periods).

Results During 2016-2018, the number of prevalent patients diagnosed with PSO was 194,054 (2016), 210,830 (2017), and 225,171 (2018). The percentage of patients receiving biologics or targeted synthetic agents ranged from 1.5 to $2.1 \%$. Among them, naïve patients receiving interleukin (IL) inhibitors increased from $37.5 \%$ (2016) to $69.4 \%$ (2018), while those receiving anti-tumor necrosis factor (anti-TNF) decreased from 62.5\% (2016) to 30.6\% (2018). The longitudinal analysis included 894 and 1218 naïve patients in 2014 and 2017, respectively, of whom 7.2\% (2014) and 6.9\% (2017) switched therapy after a mean of 7.1 (2014) and 6.9 (2017) months. Overall, 259 patients were prescribed ixekizumab starting in 2017, of whom $73 \%$ were naïve. Ixekizumab was prescribed as monotherapy to $52.5 \%$.
\end{abstract}

Conclusions The proportion of patients receiving biologics appeared constant over the years, with an increasing number of naïve patients being prescribed IL-17 inhibitors. Ixekizumab patients were mostly naïve.

\section{Key Points}

A picture of psoriasis (PSO) management in Italian clinical practice settings is provided, with a focus on recently approved biologic treatments.

A PSO prevalence of $2.3 \%$ for Italy was reported.

Among PSO patients receiving biologic agents, an increasing trend of prescriptions of interleukin inhibitors was observed over the years.

Valentina Perrone

valentina.perrone@ clicon.it

1 CliCon S.r.1., Società Benefit Health Economics and Outcomes Research, Via Murri, 9 40137, Bologna, Italy

2 Eli Lilly Italy S.p.A., Sesto Fiorentino, Italy

3 Eli Lilly Italy S.p.A., Roma, Italy

\section{Introduction}

Psoriasis (PSO) is a chronic immune-mediated inflammatory disease that comprises a wide spectrum of dermatological manifestations depending on the clinical features and severity of the disease [1]. Even though the etiology of PSO is not fully understood, there is a connection between environmental factors and genetic susceptibility [2]. In fact, some environmental factors, such as stress and infection, can trigger or exacerbate the disease $[3,4]$.

The typical cutaneous manifestations and chronic course of PSO have a significant impact on patients' quality of life, as the disease is associated with potential psychological and social consequences [5]. Moreover, in patients with severe disease, there is a higher risk of mortality than in the general population (hazard ratio 1.5; $95 \%$ confidence interval 1.3-1.7) [6,7].

The prevalence of PSO among the adult Italian population is estimated to be $2.7 \%$, with an increasing trend up 
to $3.5 \%$ for individuals aged 60-64 years, followed by a steady decrease to $1.7 \%$ for those over 74 years of age [8].

The diagnosis of PSO is usually clinical and based mainly on a physical examination and the patient's medical history; skin biopsy is rarely needed to confirm the diagnosis [9].

There are several forms of PSO, although plaque psoriasis (PP) is the most common (approximately $80 \%$ of patients) $[10,11]$. PP is characterized by the presence of erythematous-desquamative lesions with clear margins, mainly located on the limbs (knees and elbows), lumbosacral region, and scalp, often accompanied by symptoms such as itching and pain [12]. Approximately $20 \%$ of patients develop moderate-to-severe PP [13, 14].

Traditionally, medical treatment options for psoriatic patients are topical agents, oral systemic agents, and phototherapies [15]. Over the past decades, a better understanding of PSO pathophysiology has allowed the development of several therapeutic options as targeted therapies, including biologics and small molecules, that substantially alter the treatment landscape for psoriasis [16].

According to the Italian guidelines of PSO management, treatment decisions depend on different disease characteristics, such as severity, lesion location, patient quality of life, comorbidities, and drug features [14].

Topical therapy alone is indicated for mild forms of PSO, but it can be used in combination with systemic treatment for patients with moderate-to-severe PSO [14].

Conventional systemic therapies consist of acitretin, methotrexate, and cyclosporin; targeted treatments currently approved in Italy include apremilast [phosphodiesterase 4 (PDE4) inhibitor], anti-tumor necrosis factor alpha (anti-TNF) agents (adalimumab, certolizumab, etanercept, and infliximab), and interleukin (IL) inhibitors (ustekinumab, an inhibitor of IL-12/23; secukinumab, ixekizumab, and brodalumab, inhibitors of IL-17; and guselkumab and tildrakizumab, inhibitors of IL-23).

Since PSO is a lifelong relapsing-remitting disease, patients often require lifelong therapies. Randomized clinical trials (RCTs), even when investigating long-term treatment outcomes, do not reflect clinical practice. Therefore, real-world data could be useful for evaluating the effectiveness, clinical use, and prescribing patterns of therapies in the long term in the context of a clinical practice setting.

The aims of the present study were to evaluate the treatment patterns of biological/targeted synthetic disease-modifying antirheumatic drugs (b/tsDMARDs) and to analyze pharmacoutilization in patients treated for PSO in a realworld Italian setting, with a focus on recently introduced biological therapies.

\section{Methods}

\subsection{Data Source}

A retrospective observational study was performed by integrating the administrative databases of a pool of Italian Healthcare Entities. These databases contain all the information regarding the healthcare resources reimbursed by the Italian National Healthcare Service (INHS), which is based on the principle of universal coverage for all Italian citizens. According to the objectives of the analysis, the following databases were used: beneficiary database (data on patients' characteristics), pharmaceutical database [data on prescription of drugs reimbursed by the INHS, including the drug name, Anatomical Therapeutic Chemical (ATC) code, and dispensing date], hospitalization database [including primary and secondary diagnoses at hospital discharge and procedures classified according to the International Classification of Diseases, Ninth Revision, Clinical Modification (ICD-9-CM) (ICD-10-CM not yet available)], and payment exemption database (including disease exemption codes).

To guarantee patients' privacy, an anonymous univocal numeric code was assigned to each subject included in the study, ensuring full compliance with the European General Data Protection Regulation (GDPR) (2016/679). This code allowed the electronic linkage of all records for each subject across the databases. No identifiers related to patients were provided to the authors. All the results of the analyses were produced as aggregated summaries, and the data could not be assigned, either directly or indirectly, to individual patients. Based on the pronouncement of the Data Privacy Guarantor Authority (General Authorisation for personal data treatment for scientific research purposes-n.9/2014), informed consent was not required, as its collection would be impossible for organizational reasons. According to the Italian law on the conduction of observational analyses, the ethics committee of each participating entity was notified and approved the study.

\subsection{Study Population}

All patients diagnosed with PSO were screened for study eligibility. Patients were included if they presented one of the following criteria used to identify PSO diagnosis [17]: (1) a hospitalization discharge diagnosis of PSO (ICD-9-CM code: 696.1) or (2) an exemption code (code that allows avoidance of the economic contribution for services/treatments in presence of certain diseases) for PSO (045.696.1) or (3) a prescription for anti-psoriatic topical drugs (ATC code: D05A) (diagnosis by proxy). 
To describe patient characteristics and treatment patterns based on the most up-to-date data available, two different approaches were involved:

Cross-sectional analysis: Patients fulfilling the inclusion criteria during the period from 2016 to 2018 were analyzed. The years were not mutually exclusive; therefore, patients could be present in each calendar year. The index date (ID) was defined as the first date on which the patients met one of the inclusion criteria each year. Patients who received a prescription for drugs indicated for PSO at the ID were defined as "treated"; otherwise, they were regarded as "untreated."

Longitudinal analysis: Three distinct longitudinal analyses were performed on patients diagnosed with PSO according to the inclusion criteria who also received a b/ tsDMARD prescription to evaluate the pharmacoutilization of these therapies. Patients without b/tsDMARDs 1 year before the ID were defined as "naïve," while those already under b/tsDMARD treatment 1 year before the ID were defined as "experienced". Three longitudinal cohorts were created; two of them included naïve patients during year 2014 and year 2017 (the inclusion periods), while the third cohort included experienced patients from 2018. The ID was the date of the first b/tsDMARD prescription during the inclusion periods. Follow-up was 1 year from the ID. Moreover, a focus on ixekizumab utilization and prescribing patterns was provided, within an analysis period from 2017 to the end of data availability (end dates differed depending on data availability for each healthcare entity).

\subsection{Study Variables}

At baseline, data on demographic characteristics such as age and sex were collected.

All patients included had at least 1 year of data availability prior to the ID. The following comorbidities were examined considering all available data before the ID: rheumatoid arthritis (ICD-9-CM: 714, exemption code: 006), psoriatic arthritis (PsA) (ICD-9-CM: 696.0, exemption code: 045.696.0), axial spondyloarthritis (axSpA) (ICD-9-CM: 720, exemption code: 054.720.0), Crohn's disease (ICD9-CM: 555, exemption code: 009.555), ulcerative colitis (ICD-9-CM: 556, exemption code: 009.556), and cardiovascular conditions [acute myocardial infarction and other forms of ischemic heart disease (ICD-9-CM: 410, 411), cerebrovascular disease (ICD-9-CM: 430-438), and other cardiovascular-related hospitalizations (ICD-9-CM codes: 413, 414, 440, 443)]. The presence of comorbidities was also measured using the Charlson Comorbidity Index (CCI) [18], which assigns a weighted score to each concomitant disease identified from discharge diagnoses/pharmaceutical prescriptions recorded in the 12 months prior to the ID (if $0, \mathrm{CCI}$ is null).

The following $\mathrm{b} / \mathrm{tsDMARDs}$ indicated for PSO treatment were analyzed: adalimumab (ATC: L04AB04), apremilast (ATC: L04AA32), etanercept (ATC: L04AB01), infliximab (ATC: L04AB02), ixekizumab (ATC: L04AC13), secukinumab (ATC: L04AC10), and ustekinumab (ATC: L04AC05).

Switch of therapy was assessed during the first year of follow-up and was defined as the changing of a b/tsDMARD other than that administered at the ID, and the mean time to the switch was measured in months.

All analyses were descriptive. Continuous variables are reported as the mean \pm standard deviation (SD), whereas categorical variables are expressed as frequencies and percentages.

All analyses were performed using STATA SE version 12.0 (StataCorp LP, College Station, TX, USA).

\section{Results}

Based on the sample population, the prevalence of PSO was estimated to be $2.3 \%$ (2.7\% among the adult population). A comprehensive study diagram for cross-sectional and longitudinal analyses is shown in Fig. 1. In the cross-sectional analysis, a total of 194,054 (2016), 210,830 (2017), and 225,171 (2018) patients with a diagnosis of PSO were identified (prevalent patients); their characteristics are reported in Table 1. The mean age \pm SD ranged from $56.5 \pm 14.5$ (2016) to $57.9 \pm 14.5$ (2018). The percentage of males was approximately $52 \%$ for all years considered. PsA was a concomitant condition in $1.3-1.6 \%$ of patients, whereas axSpA was observed in $0.2 \%$ of patients in each year analyzed. In $2016,47.8 \%$ of patients were untreated, $50.4 \%$ were treated with conventional systemic therapies/nonsteroidal antiinflammatory drugs (NSAIDs)/topical agents, and $1.8 \%$ were treated with b/tsDMARDs. In 2017, 50.6\%, 47.4\%, and 2.1\% were untreated, treated with conventional systemic therapies/NSAIDs/topical agents, and treated with b/tsDMARDs, respectively. In $2018,66.5 \%, 32 \%$, and $1.5 \%$ were untreated, treated with conventional systemic therapies/NSAIDs/topical agents, and treated with b/tsDMARDs, respectively. However, the 2018 results must be interpreted with caution due to the partial availability of data provided. Among the b/tsDMARD treatment group, the overall use of IL or PDE4 inhibitors increased over time versus TNF $\alpha$ inhibitors, from $26.7 \%$ in 2016 to $50.1 \%$ in 2018 (Table 2), particularly among naïve patients (from $37.5 \%$ in 2016 to $69.4 \%$ in 2018). As shown in Table 3, the proportion of prescriptions for the PDE4 inhibitor apremilast remained stable at approximately 4.2-4.8\% during 2017 and 2018, while prescriptions 
Fig. 1 Study diagram of cross-sectional and longitudinal analyses. $M$ million, $P S O$ psoriasis

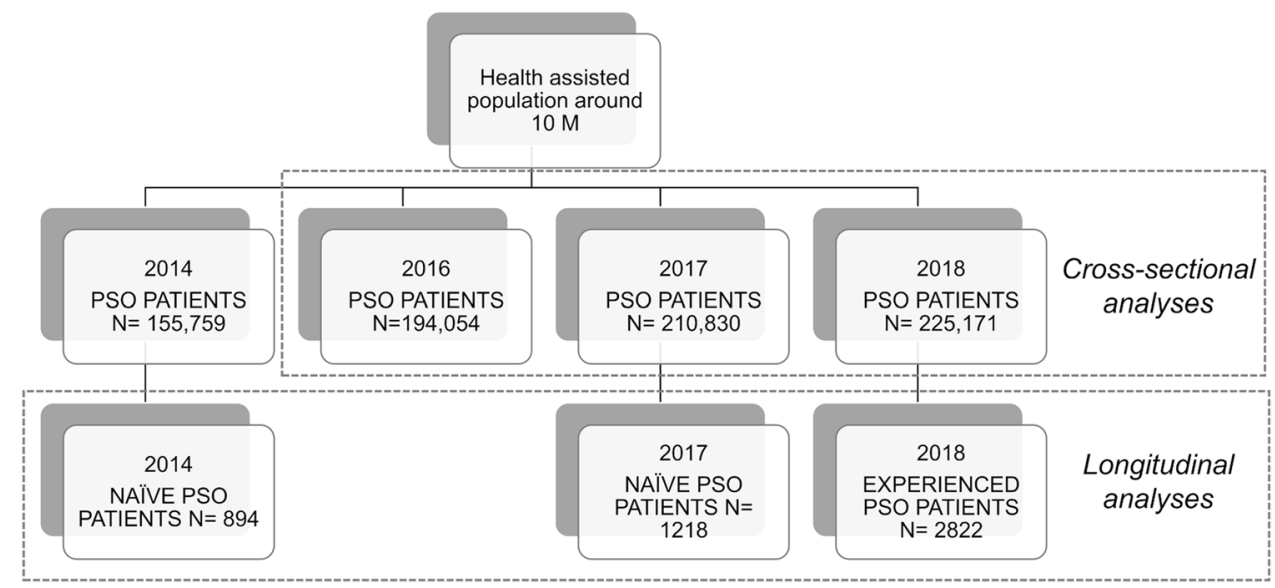

Table 1 Cross-sectional analysis: baseline demographic and clinical characteristics of PSO patients

\begin{tabular}{|c|c|c|c|}
\hline & 2016 & 2017 & 2018 \\
\hline Diagnosed, $n$ & 194,054 & 210,830 & 225,171 \\
\hline Age (mean, SD) & $56.5(14.5)$ & $57.2(14.5)$ & $57.9(14.5)$ \\
\hline Male, $n(\%)$ & $101,474(52.3)$ & $110,158(52.2)$ & $117,543(52.2)$ \\
\hline \multicolumn{4}{|c|}{ Presence of comorbidities } \\
\hline $\mathrm{RA}, n(\%)$ & $1870(1.0)$ & $2113(1.0)$ & $2386(1.1)$ \\
\hline axSpA, $n(\%)$ & $304(0.2)$ & $348(0.2)$ & $408(0.2)$ \\
\hline PsA, $n(\%)$ & $2585(1.3)$ & $3004(1.4)$ & $3521(1.6)$ \\
\hline $\mathrm{CD} / \mathrm{UC}, n(\%)$ & $786(0.4)$ & $900(0.4)$ & $1037(0.5)$ \\
\hline $\begin{array}{l}\text { Cardiovascular, } \\
n(\%)\end{array}$ & $674(0.3)$ & $877(0.4)$ & $643(0.3)$ \\
\hline $\begin{array}{l}\text { Charlson Comor- } \\
\text { bidity Index } \\
\text { (mean, SD) }\end{array}$ & $0.0(0.1)$ & $0.0(0.1)$ & $0.0(0.1)$ \\
\hline
\end{tabular}

axSpA axial spondyloarthritis, $C D / U C$ Crohn's disease/ulcerative colitis, $P S A$ psoriatic arthritis, $P S O$ psoriasis, $R A$ rheumatoid arthritis, $S D$ standard deviation for the IL inhibitors ixekizumab and secukinumab showed an upward trend over the years analyzed (from $0.5 \%$ in 2016 to $3.6 \%$ in 2017 and from $3.3 \%$ in 2016 to $22.2 \%$ in 2018 for ixekizumab and secukinumab, respectively); conversely, prescriptions for the IL inhibitor ustekinumab slightly declined, from $23.4 \%$ in 2016 to $19.5 \%$ in 2018 . The same trends were observed among naïve patients. In parallel, the use of antiTNF agents decreased among all $\mathrm{b} / \mathrm{tsDMARD}$ patients, from $73.3 \%$ (2016) to $49.9 \%$ (2018), and among naïve users, from $62.5 \%$ (2016) to $30.6 \%$ (2018) (Table 2).

In the longitudinal analysis, 894 and 1218 naïve patients were included in 2014 and 2017, respectively. In the 2014 cohort, $7.2 \%$ of patients experienced their first treatment switch during the first year of follow-up, after a mean time of 7.1 months, while in the 2017 cohort, $6.9 \%$ of patients experienced their first treatment switch during the first year of follow-up, with a mean time of 6.9 months (Table 4). In both periods, switching was more frequently observed among adalimumab and etanercept users $(9.3 \%$ and $8 \%$ in $2014,8 \%$ and $10.9 \%$ in 2017 , respectively). Of the 2822
Table 2. Cross-sectional analysis: biologic treatment patterns per calendar year in PSO patients overall, naïve and experienced

\begin{tabular}{llll}
\hline & 2016 & 2017 & 2018 \\
\hline b/tsDMARDs users, $n$ & 3439 & 4436 & 3452 \\
IL-17 or IL-12/23 or PDE4 inhibitors, $n(\%)$ & $919(26.7)$ & $1836(41.4)$ & $1730(50.1)$ \\
Anti-TNF agents, $n(\%)$ & $2520(73.3)$ & $2600(58.6)$ & $1722(49.9)$ \\
Naïve, $n(\%)$ & $619(18.0)$ & $1213(27.3)$ & $630(18.3)$ \\
IL-17 or IL-12/23 or PDE4 inhibitors, $n(\%)$ & $232(37.5)^{*}$ & $739(60.9)^{*}$ & $437(69.4)^{*}$ \\
Anti-TNF agents, $n(\%)$ & $387(62.5)^{*}$ & $474(39.1)^{*}$ & $193(30.6)^{*}$ \\
Experienced, $n(\%)$ & $2820(82.0)$ & $3223(72.7)$ & $2822(81.7)$ \\
IL-17 or IL-12/23 or PDE4 inhibitors, $n(\%)$ & $687(24.4)^{* *}$ & $1097(34.0)^{* *}$ & $1293(45.8)^{* *}$ \\
Anti-TNF agents, $n(\%)$ & $2133(75.6)^{* *}$ & $2126(66.0)^{* *}$ & $1529(54.2)^{* *}$ \\
\hline
\end{tabular}

b/tsDMARD biological/targeted synthetic disease-modifying antirheumatic drug, IL interleukin, PDE4 phosphodiesterase 4, PSO psoriasis, TNF tumor necrosis factor

*Percentage among naïve patients

${ }^{* *}$ Percentage among experienced patients 
Table 3 Cross-sectional analysis: b/tsDMARD distribution per calendar year

\begin{tabular}{llllllll}
\hline & \multicolumn{3}{l}{ Total PSO population } & & & \multicolumn{2}{l}{ Naïve PSO population } \\
\cline { 2 - 3 } & 2016 & 2017 & 2018 & & 2016 & 2017 & 2018 \\
\hline b/tsDMARD users, $n$ & 3439 & 4436 & 3452 & & 619 & 1213 & 630 \\
Adalimumab, $n(\%)$ & $1140(33.1)$ & $1292(29.1)$ & $832(24.1)$ & & $211(34.3)$ & $284(23.5)$ & $87(14.1)$ \\
Apremilast, $n(\%)$ & $0(0.0)$ & $187(4.2)$ & $165(4.8)$ & & $0(0.0)$ & $184(15.2)$ & $99(15.7)$ \\
Etanercept, $n(\%)$ & $1127(32.8)$ & $1081(24.4)$ & $718(20.8)$ & & $140(22.4)$ & $165(13.5)$ & $81(12.7)$ \\
Infliximab, $n(\%)$ & $253(7.4)$ & $227(5.1)$ & $172(5.0)$ & & $36(5.8)$ & $26(2.1)$ & $25(3.9)$ \\
Ixekizumab, $n(\%)$ & $0(0.0)$ & $24(0.5)$ & $124(3.6)$ & & $0(0.0)$ & $24(2.0)$ & $70(11.0)$ \\
Secukinumab, $n(\%)$ & $113(3.3)$ & $700(15.8)$ & $767(22.2)$ & & $76(12.2)$ & $326(27.0)$ & $201(32.1)$ \\
Ustekinumab, $n(\%)$ & $806(23.4)$ & $925(20.9)$ & $674(19.5)$ & & $156(25.3)$ & $204(16.7)$ & $67(10.5)$ \\
\hline
\end{tabular}

b/tsDMARD biological/targeted synthetic disease-modifying antirheumatic drug, PSO psoriasis experienced patients included from 2018, 4.8\% switched treatment during the first year of follow-up, with a mean time of 6.7 months (Table 5).

A subsequent analysis focused on patients prescribed IL-17 inhibitors that have been recently approved and are reimbursable by the Ministry of Health in Italy for the treatment of moderate-to-severe PSO. To ensure a sufficient observation period based on data availability, the analysis considered the utilization of ixekizumab, which was approved in 2017. A total of 259 ixekizumab patients (mean age of $50.7 \pm 13.3$ years, $65.3 \%$ male) were identified and followed up for a mean time of $14.0 \pm 6.7$ months. Of them, $11.6 \%$ had a concomitant diagnosis of PsA, and $3.9 \%$ had cardiovascular conditions. At the ID, 52.5\% received ixekizumab as monotherapy, while the remaining patients were prescribed NSAIDs, conventional systemic therapy, or both. Considering all the available periods before the ID, 73\% $(N=189)$ of those patients were naïve, and $14.7 \%(N=38)$ and $6.9 \%(N=18)$ had one and two previous b/tsDMARD prescriptions, respectively. In the 12 months before the ID, the most frequently prescribed b/tsDMARDs were secukinumab (16.2\%), ustekinumab (12.4\%), and adalimumab (8.1\%). Over 12 months of follow-up, treatment switching was observed in $5.8 \%$ of patients.

\section{Discussion}

In recent decades, the management of adults with moderateto-severe PSO has been revolutionized by the introduction of biological therapies. Several RCTs have been conducted and have established the efficacy and safety profiles of these treatments; however, their performance in daily practice may be different, as elderly patients and those with comorbidities are usually excluded from clinical trials [19]. With this context in mind, this study provides some insight into the patterns of utilization of $\mathrm{b} / \mathrm{tsDMARDs}$ among patients affected by PSO in a real-world setting in Italy.
Table 4 Longitudinal analysis: treatment switching in naïve PSO patients during the first year of the follow-up period (inclusion period: 2014,2017$)$

\begin{tabular}{|c|c|c|c|c|}
\hline \multirow[t]{2}{*}{ b/tsDMARDs index } & \multirow{2}{*}{$\begin{array}{l}N \text { patients } \\
\text { at index }\end{array}$} & \multirow{2}{*}{$\begin{array}{l}\text { Months before } \\
\text { switch (mean) }\end{array}$} & \multicolumn{2}{|c|}{$N(\%)$ of switch } \\
\hline & & & 1 & 2 \\
\hline \multicolumn{5}{|l|}{ Inclusion period: 2014} \\
\hline Adalimumab & 333 & 6.6 & $31(9.3)$ & NI \\
\hline Etanercept & 339 & 7.2 & $27(8.0)$ & NI \\
\hline Infliximab & 34 & NI & NI & $0(0.0)$ \\
\hline Ustekinumab & 188 & 9.6 & $5(2.7)$ & $0(0.0)$ \\
\hline Total & 894 & 7.1 & $64(7.2)$ & $5(0.6)$ \\
\hline \multicolumn{5}{|l|}{ Inclusion period: 2017} \\
\hline Adalimumab & 286 & 8.4 & $23(8.0)$ & $0(0.0)$ \\
\hline Apremilast & 184 & 5.5 & $8(4.3)$ & $0(0.0)$ \\
\hline Etanercept & 165 & 6.3 & $18(10.9)$ & $0(0.0)$ \\
\hline Infliximab & 26 & NI & NI & $0(0.0)$ \\
\hline Ixekizumab & 24 & NI & NI & $0(0.0)$ \\
\hline Secukinumab & 329 & 5.8 & $17(5.2)$ & $4(1.2)$ \\
\hline Ustekinumab & 204 & 7.7 & $15(7.4)$ & NI \\
\hline Total & 1218 & 6.9 & $84(6.9)$ & $5(0.4)$ \\
\hline
\end{tabular}

Following the "Opinion 05/2014 on Anonymisation Techniques" drafted by the "European Commission Article 29 Working Party", analyses involving fewer than 3 patients were not reported, as they are potentially reconductable to single individuals. Therefore, the results referring to $\leq 3$ patients were reported as NI

b/tsDMARD biological/targeted synthetic disease-modifying antirheumatic drug, NI not issuable, $P S O$ psoriasis

According to the global report on psoriasis from the World Health Organization (WHO) [20], PSO occurs in both sexes equally and is most common in the age range of 50-69 years; the baseline characteristics of patients included in the crosssectional analysis reflected those features well. The prevalence of PSO estimated in this study (2.3\%) is in line with that $(1.8-3.1 \%)$ reported in the literature for Italy [21].

The treatment patterns shown in the cross-sectional analyses suggest a tendency of undertreatment since approximately half of the cohorts did not receive any treatment 
Table 5 Longitudinal analysis: treatment switching in experienced PSO patients during the first year of follow-up (inclusion period: 2018)

\begin{tabular}{lllll}
\hline b/tsDMARDs index & $\begin{array}{l}N \text { patients } \\
\text { at index }\end{array}$ & $\begin{array}{l}\text { Months before } \\
\text { switch (mean) }\end{array}$ & \multicolumn{2}{l}{$N(\%)$ of switch } \\
\cline { 5 - 5 } & & & 1 & 2 \\
\hline Adalimumab & 753 & 5.7 & $30(4.0)$ & $\mathrm{NI}$ \\
Apremilast & 67 & 5.5 & $4(6.0)$ & $0(0.0)$ \\
Etanercept & 645 & 7.0 & $24(3.7)$ & $\mathrm{NI}$ \\
Infliximab & 147 & 5.0 & $7(4.8)$ & $0(0.0)$ \\
Ixekizumab & 54 & $\mathrm{NI}$ & $\mathrm{NI}$ & $0(0.0)$ \\
Secukinumab & 571 & 6.5 & $52(9.1)$ & $6(1.1)$ \\
Ustekinumab & 585 & 9.0 & $16(2.7)$ & $0(0.0)$ \\
Total & 2822 & 6.7 & $136(4.8)$ & $9(0.3)$ \\
\hline
\end{tabular}

Following the "Opinion 05/2014 on Anonymisation Techniques" drafted by the "European Commission Article 29 Working Party", the analyses involving fewer than 3 patients were not reported, as they are potentially reconductable to single individuals. Therefore, the results referring to $\leq 3$ patients were reported as NI

b/tsDMARD biological/targeted synthetic disease-modifying antirheumatic drug, NI not issuable, PSO psoriasis

indicated for PSO. This is in line with a previous Italian study reporting that treatment of $54 \%$ of PSO patients attending outpatient dermatology clinics did not comply with the suggested treatment regimen [22]. The same consideration was also made by dermatologists from North America and European Countries (Italy included), who acknowledge the undertreatment of PSO and recognized patient concerns over side effects as one possible explanation [23]. Patients could seek alternative treatments: in Italy, patients commonly choose thermal spring water balneotherapy [14], which cannot be tracked in administrative databases. The treated patients in this study were mainly prescribed conventional therapies, while a small proportion (approximately $2 \%$ ) of patients in all years considered received b/tsDMARDs. This treatment distribution may reflect the heterogeneity of PSO status among the population analyzed; the absence of treatment for instance could indicate milder forms of PSO, as well as the low proportion of patients with PsA comorbidity. Furthermore, the lower percentage of patients on biologic agents may be explained by limitations related to the prescription of these agents to patients with moderate-tosevere forms [16]. Indeed, similar proportions $(0.25-2 \%)$ were observed in other studies based on claim databases [24, 25], while a Belgian cross-sectional study that focused on moderate-to-severe PP reported that $29.5 \%$ of patients were receiving biologics [26].

Regarding the patients prescribed biologics in this study, our results showed an increasing trend for prescriptions of IL inhibitors or tsDMARDs, with a consequent reduced utilization of TNF inhibitors for patients prescribed biologics; this trend was also observed among naïve patients. Similar prescribing variations among patient classes over the years were observed in other real-world studies, although different healthcare delivery settings should be considered when comparing results [27]. To date, no clinical priority has been established for the two drug classes by any guidelines [14, 28]; however, head-to-head comparison trials and metaanalyses comparing the effectiveness of intra- and interclass drugs are increasingly being published in the literature [29, 30]. The evidence found in real practice could help to contextualize the findings in a long-term manner.

The switching rate within the first year of treatment among bio-naïve patients was in line with another Italian study that collected data on naïve patients between January 1, 2010, and December 31, 2014, from administrative databases of a Southern Italian Local Health Unit. Similar to our findings in the 2014 cohort $(7.2 \%$ first and $0.6 \%$ second switch), that study showed an approximately $8 \%$ switch to another biological drug after a mean time of 140 days [31].

Within our study, we outlined a profile of patients receiving recently approved, newly available treatments, including the IL-17 inhibitor ixekizumab. Patients receiving such therapy tended to be slightly younger than the other treatment groups observed in the previous analysis and displayed a generally worse clinical profile, with a higher proportion of concomitant cardiovascular conditions or PsA comorbidities. The latter could be explained since, according to the recently published European League Against Rheumatism (EULAR) recommendations for PsA, IL-17, or IL-12/23 inhibitors are preferred in cases of relevant skin involvement [32]. Regarding the utilization of ixekizumab, most patients were first prescribed $b / t s D M A R D$, while experienced users started ixekizumab mostly after intraclass switching.

We acknowledge that our study has some limitations. Our cohort of patients reflects a real clinical practice setting, and the results must be interpreted with consideration for the limitations related to the observational nature of this study; i.e., this study is based on data collected through administrative databases. First, there was a lack of clinical information related to comorbidities, the severity of PSO, and other potential confounders that could have influenced our results; therefore, the presence of concomitant PsA may be underestimated. Since the comorbidities herein analyzed were addressed based on any available data prior to inclusion, there might be unequal capture of these variables among patients. Second, data on the use of pharmacological treatments were retrieved from medical prescription and dispensing information; data on actual drug use were not available, and the treatment patterns could also reflect the different approval dates of the therapies analyzed. Finally, primary care and private care data could not be collected. Therefore, it was not possible to assess information about primary care physicians related to the management of patients in this analysis. Furthermore, since administrative databases collect 
data on healthcare resources reimbursed by INHS, out-ofpocket topical treatments or thermal spring water balneotherapy are not captured. Ultimately, these results must be interpreted with caution, considering the partial availability of data provided for 2018, and they are limited to the population analyzed and to the therapies reimbursed for PSO at the time of the analysis, and may not be generalized to the entire Italian population.

\section{Conclusion}

This real-world analysis provides updated insights into the treatment patterns of PSO patients in Italy during 2016-2018. Our findings highlight that the proportion of patients receiving b/tsDMARDs appeared constant over the years; however, drug utilization seemed to shift towards IL inhibitors, which have been increasingly prescribed. This is in line with the rapidly evolving scenario of new and promising therapeutic options entering the market to keep up with treatment goals for PSO and the shift from a Psoriasis Area and Severity Index (PASI) 90 towards a PASI 100 response.

In the longitudinal analysis, the proportion of bio-naïve patients who switched therapy remained constant over the periods analyzed.

Moreover, we focused on the therapeutic pathway of one of the most recent bDMARD approved in Italy, ixekizumab, to provide a preliminary description of the profile of patients starting such recently approved therapies, in view of the future therapeutic options for PSO management. The results showed that this drug is mainly prescribed to younger and more comorbid (cardiovascular and PsA) patients, that most patients were b/tsDMARD-naïve, and that experienced patients were prescribed ixekizumab mainly after an intraclass switch. However, more robust data on the use of ixekizumab according to guidelines will be available in the future, considering that studies with a longer follow-up and larger sample size are expected.

Acknowledgements The present manuscript was edited for proper English language, grammar, punctuation, spelling, and overall style by Courey A. from American Journal Experts (AJE).

\section{Declarations}

Funding Eli Lilly purchased the study report that is the basis for this article. The manuscript was developed with Eli Lilly and CliCon S.r.l.

Conflict of interest VP, EG, DS, and LDE report no conflicts of interest related to this work. The agreement signed by CliCon S.r.l. and Eli Lilly does not create any entityship, joint venture, or any similar relationship between parties. CliCon S.r.l. is an independent company. Neither CliCon S.r.l. nor any of their representatives are employees of Eli Lilly for any purpose. SL, AM, and SA are employees of Eli Lilly
Italy S.p.a., Italy. MG is an employee of Eli Lilly S.p.a. \& Company Roma, Italy.

Availability of data and material All data used for the current study are available upon reasonable request to CliCon S.r.l., which is the body entitled to data treatment and analysis by Local Health Units.

Code availability Not applicable.

Ethics approval The following ethics committees were notified of this study and approved the study: Comitato Etico per la Sperimentazione Clinica delle province di Verona e Rovigo (Ref. N. 52045), approval date 25/7/2018; Comitato Etico Sezione Area Centro (Ref. N. 43), approval date 22/02/2019; Comitato Etico ASL Lecce (Ref. N. 29), approval date 11/2/2019; Comitato Etico Regione Abruzzo AvezzanoSulmona-L'Aquila (Ref. N. 0040036/19), approval date 22/11/2018; Comitato Etico Indipendente "AOU “Consorziale Policlinico" (Ref. N. 0059036), approval date 09/07/2019; Comitato etico interprovinciale Area 1 (Ref. N71/SegCE/2019), approval date 18/09/2019.

Consent to participate Not applicable.

Consent for publication Not applicable.

Author contributions Conceptualization: VP and LDE; data curation: VP and LDE; funding acquisition: LDE; methodology: DS; supervision: LDE; visualization: LDE; writing — original draft: VP and EG; writing-review and editing: VP, SL, AM, SA, and M.G. All authors have read and approved the final version of the manuscript.

Open Access This article is licensed under a Creative Commons Attribution-NonCommercial 4.0 International License, which permits any non-commercial use, sharing, adaptation, distribution and reproduction in any medium or format, as long as you give appropriate credit to the original author(s) and the source, provide a link to the Creative Commons licence, and indicate if changes were made. The images or other third party material in this article are included in the article's Creative Commons licence, unless indicated otherwise in a credit line to the material. If material is not included in the article's Creative Commons licence and your intended use is not permitted by statutory regulation or exceeds the permitted use, you will need to obtain permission directly from the copyright holder. To view a copy of this licence, visit http://creativecommons.org/licenses/by-nc/4.0/.

\section{References}

1. Sarac G, Koca TT, Baglan T. A brief summary of clinical types of psoriasis. North Clin Istanb. 2016;3:79-82. https://doi.org/10. 14744/nci.2016.16023.

2. Elder JT, Bruce AT, Gudjonsson JE, Johnston A, Stuart PE, Tejasvi T, Voorhees JJ, Abecasis GR, Nair RP. Molecular dissection of psoriasis: integrating genetics and biology. J Investig Dermatol. 2010;130:1213-26. https://doi.org/10.1038/jid.2009. 319.

3. Jariwala SP. The role of dendritic cells in the immunopathogenesis of psoriasis. Arch Dermatol Res. 2007;299:359-66. https://doi. org/10.1007/s00403-007-0775-4.

4. Lowes MA, Kikuchi T, Fuentes-Duculan J, Cardinale I, Zaba LC, Haider AS, Bowman EP, Krueger JG. Psoriasis vulgaris lesions contain discrete populations of Th1 and Th17 T cells. J Investig Dermatol. 2008;128:1207-11. https://doi.org/10.1038/sj.jid.57012 13. 
5. Kurd SK, Troxel AB, Crits-Christoph P, Gelfand JM. The risk of depression, anxiety, and suicidality in patients with psoriasis: a population-based cohort study. Arch Dermatol. 2010;146:891-5. https://doi.org/10.1001/archdermatol.2010.186.

6. Saraceno R, Mannheimer R, Chimenti S. Regional distribution of psoriasis in Italy. J Eur Acad Dermatol Venereol. 2008;22:324-9. https://doi.org/10.1111/j.1468-3083.2007.02423.x.

7. Gelfand JM, Troxel AB, Lewis JD, Kurd SK, Shin DB, Wang X, Margolis DJ, Strom BL. The risk of mortality in patients with psoriasis: results from a population-based study. Arch Dermatol. 2007;143:1493-9. https://doi.org/10.1001/archderm.143.12.1493.

8. Pezzolo E, Cazzaniga S, Colombo P, Chatenoud L, Naldi L. Psoriasis incidence and lifetime prevalence: suggestion for a higher mortality rate in older age-classes among psoriatic patients compared to the general population in Italy. Acta Derm Venereol. 2019;99:400-3. https://doi.org/10.2340/00015555-3130.

9. Boehncke WH, Schön MP. Psoriasis. Lancet. 2015;386:983-94. https://doi.org/10.1016/s0140-6736(14)61909-7.

10. Di Meglio P, Villanova F, Nestle FO. Psoriasis. Cold Spring Harb Perspect Med. 2014;4: a015354. https://doi.org/10.1101/cshpe rspect.a015354.

11. Gottlieb A, Korman NJ, Gordon KB, Feldman SR, Lebwohl M, Koo JY, Van Voorhees AS, Elmets CA, Leonardi CL, Beutner KR, Bhushan R, Menter A. Guidelines of care for the management of psoriasis and psoriatic arthritis: section 2. Psoriatic arthritis: overview and guidelines of care for treatment with an emphasis on the biologics. J Am Acad Dermatol. 2008;58:851-64. https:// doi.org/10.1016/j.jaad.2008.02.040.

12. Icen M, Crowson CS, McEvoy MT, Dann FJ, Gabriel SE, Maradit KH. Trends in incidence of adult-onset psoriasis over three decades: a population-based study. J Am Acad Dermatol. 2009;60:394-401. https://doi.org/10.1016/j.jaad.2008.10.062.

13. Pathirana D, Ormerod AD, Saiag P, Smith C, Spuls PI, Nast A, Barker J, Bos JD, Burmester GR, Chimenti S, Dubertret L, Eberlein B, Erdmann R, Ferguson J, Girolomoni G, Gisondi P, Giunta A, Griffiths C, Honigsmann H, Hussain M, Jobling R, Karvonen SL, Kemeny L, Kopp I, Leonardi C, Maccarone M, Menter A, Mrowietz U, Naldi L, Nijsten T, Ortonne JP, Orzechowski HD, Rantanen T, Reich K, Reytan N, Richards H, Thio HB, van de Kerkhof P, Rzany B. European S3-guidelines on the systemic treatment of psoriasis vulgaris. J Eur Acad Dermatol Venereol. 2009;23(Suppl 2):1-70. https://doi.org/10.1111/j.1468-3083. 2009.03389.x.

14. Gisondi P, Altomare G, Ayala F, Bardazzi F, Bianchi L, Chiricozzi A, Costanzo A, Conti A, Dapavo P, De Simone C, Foti C, Naldi L, Offidani A, Parodi A, Piaserico S, Prignano F, Rongioletti F, Stingeni L, Talamonti M, Girolomoni G. Italian guidelines on the systemic treatments of moderate-to-severe plaque psoriasis. J Eur Acad Dermatol Venereol. 2017;31:774-90. https://doi.org/ 10.1111/jdv.14114.

15. Scala E, Megna M, Amerio P, Argenziano G, Babino G, Bardazzi F, Bianchi L, Caldarola G, Campanati A, Cannavò SP, Chiricozzi A, Conti A, Damiani G, Dapavo P, De Simone C, Esposito M, Fabbrocini G, Fargnoli MC, Ferrara F, Fidanza R, Gualdi G, Guarneri C, Hansel K, Malagoli P, Malara G, Micali G, Mugheddu C, Musumeci ML, Odorici G, Offidani A, Pescitelli L, Prignano F, Raimondo A, Ribero S, Rongioletti F, Stingeni L, Trifirò C, Zanframundo S, Balato A. Patients' demographic and socioeconomic characteristics influence the therapeutic decisionmaking process in psoriasis. PLoS ONE. 2020;15: e0237267. https://doi.org/10.1371/journal.pone.0237267.

16. Gisondi P, Geat D, Pizzolato M, Girolomoni G. State of the art and pharmacological pipeline of biologics for chronic plaque psoriasis. Curr Opin Pharmacol. 2019;46:90-9. https://doi.org/ 10.1016/j.coph.2019.05.007.
17. Degli Esposti L, Perrone V, Sangiorgi D, Buda S, Andretta M, Rossini M, Girolomini G. Analysis of Drug Utilization and Health Care Resource Consumption in Patients with Psoriasis and Psoriatic Arthritis before and after Treatment with Biological Therapies. Biologics. 2018;12:151-158. https://doi.org/10.2147/BTT. S16869118.Charlson ME, Pompei P, Ales KL, MacKenzie CR. A new method of classifying prognostic comorbidity in longitudinal studies: development and validation. J Chronic Dis. 1987;40:37383. https://doi.org/10.1016/0021-9681(87)90171-8

18. Charlson ME, Pompei P, Ales KL, MacKenzie CR. A new method of classifying prognostic comorbidity in longitudinal studies: development and validation. J Chronic Dis. 1987;40:373-83. https://doi.org/10.1016/0021-9681(87)90171-8.

19. Costanzo A, Malara G, Pelucchi C, Fatiga F, Barbera G, Franchi A, Galeone C. Effectiveness end points in real-world studies on biological therapies in psoriasis: systematic review with focus on drug survival. Dermatology (Basel). 2018;234:1-12. https://doi. org/10.1159/000488586.

20. Michalek IM, Loring B, John SM. Global report on psoriasis. Geneva, Switzerland: World Health Organization; 2016.

21. Prignano F, Rogai V, Cavallucci E, Bitossi A, Hammen V, Cantini F. Epidemiology of psoriasis and psoriatic arthritis in Italy-a systematic review. Curr Rheumatol Rep. 2018;20:1-12. https:// doi.org/10.1007/s11926-018-0753-1.

22. Altobelli E, Marziliano C, Fargnoli MC, Petrocelli R, Maccarone M, Chimenti S, Peris K. Current psoriasis treatments in an Italian population and their association with socio-demographical and clinical features: current frequency of treatments in Italian psoriatic patients. J Eur Acad Dermatol Venereol. 2011;26:976-82. https://doi.org/10.1111/j.1468-3083.2011.04196.x.

23. van de Kerkhof PCM, Reich K, Kavanaugh A, Bachelez H, Barker J, Girolomoni G, Langley RG, Paul CF, Puig L, Lebwohl MG. Physician perspectives in the management of psoriasis and psoriatic arthritis: results from the population-based multinational assessment of psoriasis and psoriatic arthritis survey. J Eur Acad Dermatol Venereol. 2015;29:2002-10. https://doi.org/10.1111/ jdv.13150.

24. Rencz F, Kemény L, Gajdácsi JZ, Owczarek W, Arenberger P, Tiplica GS, Stanimirović A, Niewada M, Petrova G, Marinov LT, Péntek M, Brodszky V, Gulácsi L. Use of biologics for psoriasis in Central and Eastern European countries. J Eur Acad Dermatol Venereol. 2015;29:2222-30. https://doi.org/10.1111/jdv.13222.

25. Grellmann C, Dombrowsky W, Fabricius V, Suruki R, Sheahan A, Joeres L. Epidemiology and treatment of patients with rheumatoid arthritis, psoriatic arthritis and psoriasis in Germany: a real-world evidence study. Adv Ther. 2020;38:366-85. https:// doi.org/10.1007/s12325-020-01522-8.

26. Lambert J, Ghislain PD, Lambert J, Cauwe B, Van den Enden M. Treatment patterns in moderate-to-severe plaque psoriasis: results from a Belgian cross-sectional study (DISCOVER). J Dermatol Treat. 2016;28:394-400. https://doi.org/10.1080/09546634.2016. 1255304.

27. Galli E, Liu G, Leslie D, Kirby J, Miller JJ. Prescription pattern variability of biologic therapies in treating psoriasis. J Psoriasis Psoriatic Arthritis. 2018;3:84-7. https://doi.org/10.1177/24755 30318781308.

28. Menter A, Strober BE, Kaplan DH, Kivelevitch D, Prater EF, Stoff B, Armstrong AW, Connor C, Cordoro KM, Davis DMR, Elewski BE, Gelfand JM, Gordon KB, Gottlieb AB, Kavanaugh A, Kiselica M, Korman NJ, Kroshinsky D, Lebwohl M, Leonardi CL, Lichten J, Lim HW, Mehta NN, Paller AS, Parra SL, Pathy AL, Rupani RN, Siegel M, Wong EB, Wu JJ, Hariharan V, Elmets CA. Joint AAD-NPF guidelines of care for the management and treatment of psoriasis with biologics. J Am Acad Dermatol. 2019;80:1029-72. https://doi.org/10.1016/j.jaad.2018.11.057. 
29. Sawyer LM, Malottki K, Sabry-Grant C, Yasmeen N, Wright E, Sohrt A, Borg E, Warren RB. Assessing the relative efficacy of interleukin-17 and interleukin-23 targeted treatments for moderate-to-severe plaque psoriasis: a systematic review and network meta-analysis of PASI response. PLoS ONE. 2019;14: e0220868. https://doi.org/10.1371/journal.pone.0220868.

30. Loos AM, Liu S, Segel C, Ollendorf DA, Pearson SD, Linder JA. Comparative effectiveness of targeted immunomodulators for the treatment of moderate-to-severe plaque psoriasis: a systematic review and network meta-analysis. J Am Acad Dermatol. 2018;79:135-44.e7. https://doi.org/10.1016/j.jaad.2018.02.027.

31. Guerriero F, Orlando V, Monetti VM, Russo V, Menditto E. Biological therapy utilization, switching, and cost among patients with psoriasis: retrospective analysis of administrative databases in Southern Italy. Clin Outcomes Res. 2017;9:741-8. https://doi. org/10.2147/CEOR.S147558.

32. Gossec L, Baraliakos X, McInnes I, Kerschbaumer A, de Wit M, Dougados M, Primdahl J, van der Heijde D, Smolen JS. EULAR recommendations for the management of psoriatic arthritis with pharmacological therapies: 2019 update. Ann Rheum Dis. 2020;79:700-12. https://doi.org/10.1136/annrh eumdis-2020-217159. 